\title{
Prolonged Glial Expression of Sox 4 in the CNS Leads to Architectural Cerebellar Defects and Ataxia
}

\author{
Melanie Hoser, ${ }^{1}$ Stephan L. Baader, ${ }^{2,3}$ Michael R. Bösl, ${ }^{4}$ Alice Ihmer, ${ }^{2}$ Michael Wegner, ${ }^{1}$ and Elisabeth Sock ${ }^{1}$ \\ ${ }^{1}$ Institut für Biochemie, Emil-Fischer-Zentrum, Universität Erlangen, 91054 Erlangen, Germany, ${ }^{2}$ Anatomisches Institut, Universität Bonn, 53115 Bonn, \\ Germany, ${ }^{3}$ Institut für Anatomie, Universität Jena, 07743 Jena, Germany, and ${ }^{4}$ Max-Planck-Institut für Neurobiologie, 82152 Martinsried, Germany
}

\begin{abstract}
Sox proteins of group $\mathrm{C}$ are strongly expressed in the developing nervous system and have been associated with maturation of neurons and glia. Here, we overexpressed the group C protein Sox 4 in transgenic mice under the control of the human GFAP promoter. Transgene expression was detected in radial glia and astrocytes throughout the CNS. The transgenic mice were ataxic and exhibited hydrocephaly as well as cerebellar malformations. In the cerebellum, fissures were not formed and neuronal layering was dramatically disturbed. Nevertheless, all neuronal cell types of the cerebellum were present as well as cells with characteristics of early radial glia, astrocytes, and oligodendrocytes. However, radial glia failed to migrate into the position normally taken by Bergmann glia and did not extend radial fibers toward the pial surface. The cerebellar malformations can therefore be explained by the absence of functional Bergmann glia. We conclude that Sox4 expression counteracts differentiation of radial glia and has to be downregulated before full maturation can occur.
\end{abstract}

Key words: Sry-box; high-mobility group; Sox4; Bergmann glia; astrocyte; cerebellum

\section{Introduction}

Many of the 20 mammalian members of the Sox family of transcription factors are strongly expressed in the developing CNS (Wegner, 1999; Bowles et al., 2000). Reported functions include maintenance of pluripotency and stem cell characteristics in neuroepithelial cells for group B Sox proteins, as well as specification and differentiation of glia for group E Sox proteins (Wegner and Stolt, 2005).

Sox 4 and Sox11, which make up group C together with Sox12, are also strongly expressed in the developing CNS (Uwanogho et al., 1995; Hargrave et al., 1997; Kuhlbrodt et al., 1998). Despite minor differences in regional expression levels, there is a significant overlap in the spatiotemporal expression patterns of Sox4 and Sox11 (Cheung et al., 2000). Both group C Sox proteins are predominantly found in cells that have already undergone specification but have not yet acquired their definitive differentiated phenotype. They are found in neuronal as well as glial precursors (Kuhlbrodt et al., 1998; Cheung et al., 2000). As a consequence, group $\mathrm{C}$ proteins are expressed at early stages throughout the subventricular zone (Uwanogho et al., 1995) and with decreasing rates of neurogenesis in the late embryonic and early postnatal CNS become confined to regions of imminent or ongoing differentiation (Kuhlbrodt et al., 1998). In contrast, fully differentiated neurons or glia do not appear to express either Sox protein $(\mathrm{Ku}-$ hlbrodt et al., 1998; Cheung et al., 2000).

From their expression pattern, Sox4 and Sox11 have been

Received 0ct. 27, 2006; accepted April 17, 2007

This work was supported by Wilhelm-Sander Stiftung Grant 2002.048.1 (M.W.) and Deutsche Forschungsgemeinschaft Grant So251/3-1 (E.S.). We thank F. Kirchhoff for providing the GFAP promoter.

Correspondence should be addressed to Dr. Michael Wegner, Institut für Biochemie, Universität Erlangen, Fahrstrasse 17, 91054 Erlangen, Germany. E-mail: m.wegner@biochem.uni-erlangen.de.

DOI:10.1523/JNEUROSCI.1384-07.2007

Copyright $\odot 2007$ Society for Neuroscience $\quad$ 0270-6474/07/275495-11\$15.00/0 hypothesized to be involved in neuronal and glial maturation (Hargrave et al., 1997; Kuhlbrodt et al., 1998). Evidence for a role in neuronal differentiation has been obtained recently by electroporation studies in the early chicken neural tube (Bergsland et al., 2006). In mice, however, such a function has not been confirmed so far because the CNS develops normally on a gross anatomical level in Sox4-deficient embryos (Cheung et al., 2000) as well as in Sox11-deficient embryos (Sock et al., 2004). The lack of an obvious phenotype in the mouse mutants is likely attributable to coexpression and functional equivalence of these highly related Sox family members. To avoid functional compensation, Sox 4 and Sox11 would thus have to be simultaneously deleted. However, because of the many additional defects in both mouse mutants (Schilham et al., 1996; Sock et al., 2004), constitutively doubledeficient embryos cannot be obtained.

With loss-of-function studies currently not feasible in the mouse, we chose to address the role of group $\mathrm{C}$ proteins in overexpression studies and generated transgenic mice in which a Sox4 transgene is expressed from the human GFAP promoter, which drives expression in radial glia as well as astrocytes. Here, we describe that the transgenic mice suffer from severe cerebellar ataxia that resulted from a failure of Bergmann glia to undergo correct cytoarchitectural differentiation in the developing cerebellum. Continued Sox4 expression thus interferes with maturation of radial glia. We propose that occurrence of group C Sox proteins is incompatible with terminal differentiation and may be needed to keep cells in an immature state.

\section{Materials and Methods}

Construction of transgene, generation of transgenic animals, and determination of transgene copy numbers. A $2.2 \mathrm{~kb}$ DNA fragment spanning positions -2163 to +47 of the human GFAP promoter (Brenner et al., 1994; Nolte et al., 2001) was inserted between NheI and EcoRI sites of 
pIRES2-EGFP (Clontech, Heidelberg, Germany), before $2 \mathrm{~kb}$ of rat Sox4 sequences including the complete open reading frame were placed as an EcoRI fragment between GFAP promoter and IRES-EGFP-polyA cassette (see Fig. 1A). The transgene was separated from the vector backbone by a NheI/AscI digest, purified, and microinjected into the male pronucleus of fertilized FVB/N oocytes. Transgenic mice were generated from injected oocytes according to standard techniques. Founder mice and transgenic offspring were identified by PCR analysis of DNA prepared from tail biopsies using 5'-TCGCCAGTCTAGCCCACTCC-3' and 5'GAAAGCGACATCGTCTCTAGC-3' as primers. A 426 bp PCR product was indicative of the transgene. Three female founders and one male founder were obtained.

The number of integrated transgenes was determined by Southern blotting with a $600 \mathrm{bp}$ probe spanning the region of Sox 4 behind the coding sequences for the HMG domain. This probe hybridized in genomic DNA digested with EcoRI to a $3.4 \mathrm{~kb}$ fragment of the Sox4 gene and a $2 \mathrm{~kb}$ fragment of the Sox 4 transgene. Copy numbers were determined as the ratio of band intensities for Sox 4 gene versus Sox 4 transgene after quantification on a phosphorimager.

All postnatal analyses described here were performed on progeny from the female founders bred with FVB/N wild-type males. Embryos from $10.5 \mathrm{~d}$ postcoitum $(\mathrm{dpc})$ to $18.5 \mathrm{dpc}$ were obtained from staged pregnancies and were offspring of the male founder.

Quantitative reverse transcription-PCR analysis. Total RNA was extracted from cerebellum and forebrain at postnatal day 15 (P15) using TRIZOL reagent (Invitrogen, Karlsruhe, Germany). Two micrograms of each RNA sample were reverse transcribed into cDNA for $1 \mathrm{~h}$ at $37^{\circ} \mathrm{C}$, using $200 \mathrm{U}$ of Moloney murine leukemia virus reverse transcriptase (New England Biolabs, Beverly, MA) and 100 pmol of oligo(dT) primer under standard conditions. From each cDNA, $0.5 \mu \mathrm{l}$ was amplified with primer pairs for Sox4 (5'-TCGTGAACTGCAATCGACTG-3' and 5'CGCGTTGTTGGTCTGTTGTA- ${ }^{\prime}$ ) or $\beta$-actin ( $5^{\prime}$-CCTGGGCATGGAGTCCTG- $3^{\prime}$ and $5^{\prime}$-GGAGCAATGATCTTGATCTTC- ${ }^{\prime}$ ). Primers for Sox 4 recognize transcripts from the Sox 4 gene as well as from the Sox 4 transgene. PCRs were performed on a Roche (Basel, Switzerland) Lightcycler according to the manufacturer's instructions in a $10 \mu \mathrm{l}$ reaction mixture containing $10 \%$ DMSO and $0.5 \mu \mathrm{M}$ of each primer using an annealing temperature of $56^{\circ} \mathrm{C}$.

Tissue preparation, histology, immunohistochemistry, and terminal deoxynucleotidyl transferase-mediated biotinylated UTP nick end labeling assay. At $\mathrm{P} 3, \mathrm{P} 9$, and $\mathrm{P} 15$, transgenic mice and wild-type littermates were anesthetized and perfused transcardially using $0.9 \% \mathrm{NaCl}$ solution, followed by $4 \%$ paraformaldehyde/PBS. Brains were dissected and postfixed in $4 \%$ paraformaldehyde overnight. Embryos, in contrast, were transferred immediately into $4 \%$ paraformaldehyde/PBS and kept there from $4 \mathrm{~h}$ to overnight. Afterward, tissues and embryos were washed several times in PBS, cryoprotected in 30\% sucrose, and embedded in OCT compound at $-80^{\circ} \mathrm{C}$. Alternatively, postfixed brains were thoroughly and repeatedly washed in tap water, dehydrated in a series of graded alcohols, and embedded in paraffin. Hematoxylin-eosin and Nissl staining were performed on $10 \mu \mathrm{m}$ paraffin sections; immunohistochemistry was either performed on $10 \mu \mathrm{m}$ cryosections or on $10 \mu \mathrm{m}$ paraffin sections.

For immunohistochemistry, the following primary antibodies were used in various combinations: anti-Sox10 guinea pig antiserum $(1: 1000$ dilution) (Maka et al., 2005), anti-acetylated $\alpha$ tubulin mouse monoclonal (1:100 dilution) (Woods et al., 1989), anti-NeuN mouse monoclonal (1:500 dilution, catalog \#MAB377; Millipore, Temecula, CA), anti-Tuj1 mouse monoclonal (1:5000 dilution, catalog \#MMS-435P; Covance, Denver, PA), anti-microtubule-associated protein 2 (MAP2) mouse monoclonal (1:125 dilution, catalog \#M1406; Sigma, St. Louis, MO), anti-GFAP mouse monoclonal (1:1000 dilution, catalog \#MAB360; Chemicon), anti-green fluorescent protein (GFP) mouse monoclonal (1:100 dilution, catalog \#1814460; Roche), anti-GFP rabbit antiserum (1:500 dilution, catalog \#A11122; Invitrogen), anti-brain fatty acidbinding protein (B-FABP) rabbit antiserum (1:10,000 dilution; gift of C. Birchmeier and T. Müller, Max-Delbrück-Centrum, Berlin, Germany), affinity-purified anti-Sox9 rabbit antiserum (1:2000 dilution) (Stolt et al., 2003), anti-SoxB1 rabbit antiserum (1:500 dilution) (Tanaka et al.,
2004), anti-calbindin D28K rabbit antiserum (1:3000 dilution, catalog \#CB-38; Swant, Bellinzona, Switzerland), anti-calretinin rabbit antiserum (1:2000 dilution, catalog \#7699/4; Swant), anti-Pax2 rabbit antiserum (1:200 dilution, catalog \#71-6000; Zymed, San Francisco, CA), anti-Oct6 rabbit antiserum (1:1000 dilution) (Friedrich et al., 2005), anti-Ki67 rabbit monoclonal (1:500 dilution, catalog \#RM-9106; LabVision, Fremont, CA), anti-retinoid-related orphan receptor $\alpha(\mathrm{ROR} \alpha)$ goat antiserum (1:100 dilution, catalog \#sc-6062; Santa Cruz Biotechnology, Santa Cruz, CA), and anti-Sox11 guinea pig antiserum (1:1000 dilution; M. Hoser and E. Sock, unpublished).

On cryosections, detection of immunoreactivity was with secondary antibodies conjugated to Cy2, Cy3, or Alexa Fluor immunofluorescent dyes [Dianova (Hamburg, Germany) and Invitrogen]. On paraffin sections, immunoreactivity was detected using secondary antibodies conjugated to horseradish peroxidase as diaminobenzidine precipitate. Terminal deoxynucleotidyl transferase-mediated biotinylated UTP nick end labeling (TUNEL) assays were performed according to the manufacturer's protocol (Millipore). Samples were analyzed and documented using an inverted microscope (DMIRB; Leica, Nussloch, Germany) equipped with a cooled SPOT CCD camera (Diagnostic Instruments, Heights, MI), a Leica TCS SL confocal microscope, or a Leica MZFLIII stereomicroscope equipped with an Axiocam (Zeiss, Oberkochem, Germany).

Preparation and immunocytochemical staining of cerebellar cultures. Primary cerebellar cultures were prepared from 9-d-old wild-type and transgenic pups as described previously (Baader and Schilling, 1996) and seeded in a final density of $2 \times 10^{5}$ cells per well on polylysine-coated coverslips in 24-well plates. After keeping cells for $7 \mathrm{~d}$ in Neurobasal medium (Invitrogen) containing 2\% B-27 supplement and $2 \mathrm{~mm}$ Glutamax (Invitrogen), cells were fixed in PBS containing 3\% paraformaldehyde for $15 \mathrm{~min}$. The primary and secondary antibodies were used for immunocytochemistry at a fourfold higher dilution than described for immunohistochemistry on sections.

\section{Results}

Transgenic mice that express Sox 4 under the control of human GFAP sequences display severe ataxia

The Sox 4 open reading frame was placed under the control of a $2.2 \mathrm{~kb}$ promoter fragment from the human GFAP gene (Fig. 1A). This fragment has already been successfully used to drive transgene expression in radial glia and astrocytes (Brenner et al., 1994; Nolte et al., 2001). The Sox 4 open reading frame was followed by an internal ribosomal entry site and enhanced GFP (EGFP) coding sequences (Fig. 1A). The resulting coexpression of Sox 4 and EGFP allowed us to follow the Sox4 transgene expression using EGFP autofluorescence.

We obtained three transgenic females that carried between 7 and 10 copies of the transgene as well as a transgenic male with 22 copies according to quantifications of Southern blots (Fig. 1B) (data not shown). The majority of the transgene copies were present in each founder as a concatamer at a single integration site (data not shown). All founders transmitted the transgene to their progeny with high frequency, but in the case of the male, only some offspring showed robust transgene expression.

EGFP autofluorescence was undetectable in the CNS of transgenic embryos derived from the male founder at $10.5 \mathrm{dpc}$ (Fig. $2 A)$. First signs of EGFP expression became visible in the spinal cord at $11.5 \mathrm{dpc}$ (Fig. $2 \mathrm{~B}$ ). At this time, EGFP autofluorescence was restricted to the ventralmost part of the ventricular zone. At $12.5 \mathrm{dpc}$, the EGFP signal had spread to more dorsal regions of the ventricular zone (Fig. 2C). EGFP-positive signals overlapped with SoxB1 immunoreactivity, indicating that the transgene is expressed in pluripotent proliferative precursor cells of the ventricular zone with characteristics of radial glia (Bylund et al., 2003) (Fig. 2F). As these cells leave the ventricular zone, they become specified, at $12.5 \mathrm{dpc}$, predominantly to postmitotic neuronal progenitors. These neuronal progenitors have lost SoxB1 
A

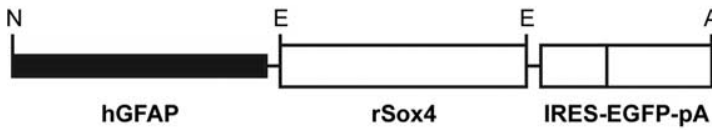

B

C
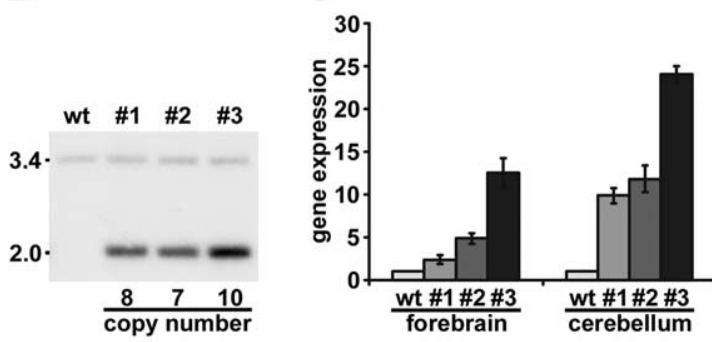

D
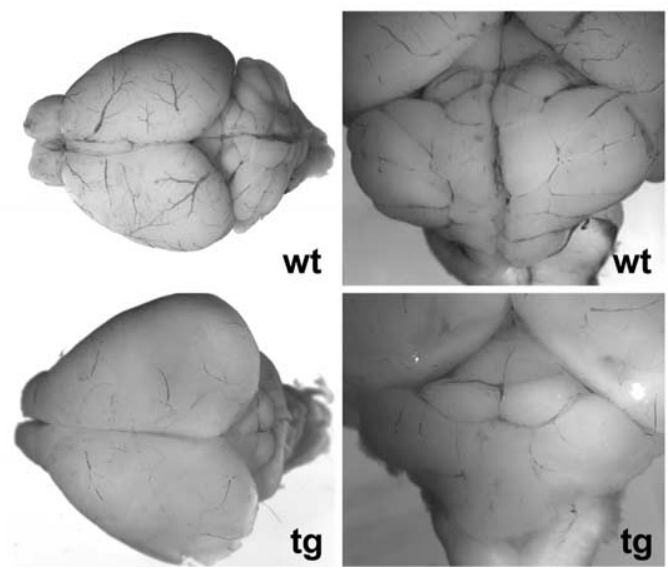

$E$

\section{A}
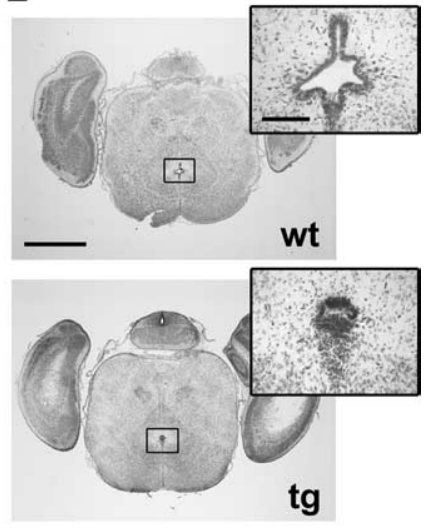

F
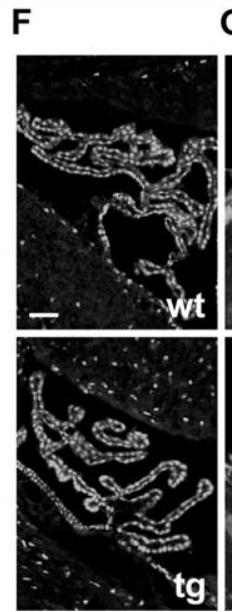

Figure 1. Generation of GFAP-Sox4 transgenic mice. $A$, Schematic representation of the GFAP-Sox4 transgene consisting of human GFAP (hGFAP) promoter (positions -2163 to +47), rat Sox4 open reading frame, and IRES-EGFP cassette. Landmark restriction sites in the construct are indicated by letters $\mathrm{N}($ Nhel), $\mathrm{E}(\mathrm{EcoRI})$, and $\mathrm{A}(\mathrm{AsCl})$. $\boldsymbol{B}$, Southern blot analysis of genomic DNA from wild-type and transgenic mice derived from female founders (\#1, \#2, \#3) after EcoRI digestion. The $3.4 \mathrm{~kb}$ band is indicative of the wild-type Sox4 gene; the $2.0 \mathrm{~kb}$ band represents the Sox4 transgene. Copy numbers were determined using a phosphorimager and are given below the lanes. C, Quantitative RT-PCR. Amounts of Sox4 transcripts were determined in total RNA prepared from forebrain and cerebellum of wild-type mice and progeny of transgenic founders at P15. Values were normalized to $\beta$-actin for each sample and expressed as multiples of the wild-type values. Error bars indicate SD. D, Gross morphology of the brain from wild-type (top) and GFAP-Sox4 transgenic (bottom) mice at P19. The right panels focus on the area of the cerebellum. Note the hydrocephalus and the strongly reduced foliation of the transgenic cerebellum. $\boldsymbol{E}$, Nissl staining of sections from the mesencephalic region of wild-type and GFAP-Sox4 transgenic brains at P3. Inlays show a magnification of the boxed areas for better visualization of the mesencephalic aqueduct. $\boldsymbol{F}$, Immunohistochemical staining of the choroid plexus of wild-type and GFAP-Sox4 transgenic mice at P15 using antibodies directed against Sox9. G, Confocal imaging of ependymal cilia in wild-type and GFAPSox4 transgenic mice at P9 after immunohistochemical staining with antibodies directed against acetylated $\alpha$ tubulin. The same magnifications were used for pictures of wild-type and transgenic cerebella. Scale bars: $\boldsymbol{E}, 1 \mathrm{~mm}$ (overview), $50 \mu \mathrm{m}$ (inlays); $\boldsymbol{F}, 50$ $\mu \mathrm{m} ; \mathbf{G}, 10 \mu \mathrm{m}$. wt, Wild type; tg, transgenic.

and gained Sox11 expression (Uwanogho et al., 1995; Bylund et al., 2003). Sox11-positive neuronal progenitors no longer expressed EGFP (Fig. 2G) and remained EGFP negative as they differentiated further to NeuN-expressing neurons (Bylund et al., 2003) (Fig. $2 H$ ). These results indicate that transgene expression is rapidly turned off on specification of radial glia to neuronal progenitors.

At $14.5 \mathrm{dpc}$, EGFP was additionally detected in astrocytes of the mantle zone (Fig. 2D). With depletion of the ventricular zone, most EGFP was associated with astrocytes at $18.5 \mathrm{dpc}$ (Fig. $2 E)$. EGFP autofluorescence continued in newborns derived from either male or female founders, indicating that the Sox4 transgene is not only efficiently turned on at early times in radial
G
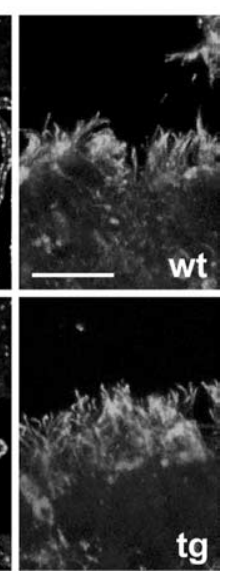

glia but continues to be expressed at later times (data not shown and Fig. 3).

To show expression of the Sox4 transgene directly, we isolated RNA from forebrain and cerebellum of 15-d-old transgenic mice derived from the three female founders and compared the transcript levels for the Sox 4 transgene to those of the normal Sox4 gene by quantitative reverse transcription (RT)-PCR. These studies show that the Sox4 transgene is expressed in the forebrain and cerebellum (Fig. 1C). In the forebrain, transgene expression levels varied significantly between the progeny from the different founders and were 2-13 times as high as Sox4 expression levels in wild-type littermates. In the cerebellum, expression levels of the Sox4 transgene were particularly high and ranged between 10 and 24 times the amount determined for Sox4 in wild-type cerebella (Fig. 1C).

Transgenic offspring derived from the three female founders developed signs of hydrocephaly and severe ataxia in the second and third postnatal week. Clinical manifestations of hydrocephalus such as dorsal doming of the calvaria and macrocrania developed progressively and were visible at P14. Even before overt signs of hydrocephaly, transgenic mice had difficulty in maintaining posture and side-toside stability. Coordination between the movements of limbs and trunk were faulty, and transgenic mice were unable to walk straight. Signs of ataxia worsened further until death, which occurred in most transgenic animals around the end of the third week. Only one transgenic mouse survived for 7 weeks. Postmortem analysis confirmed the presence of a hydrocephalus with enlargement of the lateral and third ventricles (Fig. $1 D$ and data not shown). Histological examinations of serial sections revealed a patent but significantly narrowed mesencephalic aqueduct at $\mathrm{P} 3$ and in older mice (Fig. $1 E$ and data not shown). Medial aperture and central canal were open. The cells lining the aqueduct showed a comparable morphology in GFAP-Sox 4 transgenic and wild-type mice. They were arranged normally around the aqueduct and were GFAP positive (Fig. $1 E$ and data not shown). A choroid plexus had developed in transgenic mice and exhibited no gross morphological alterations in histological stainings and Sox9 immunoreactivity (Pompolo and Harley, 2001) (Fig. $1 \mathrm{~F}$ and data not shown). Cilia were present on the ependymal cells lining the ventricles (Fig. 1G).

Suggesting a possible cause for the observed ataxia, cerebella of transgenic animals were severely hypoplastic at the time of postmortem analysis (Fig. $1 D$ ). In addition to the smaller size of transgenic cerebella, foliation was significantly reduced in both cerebellar hemispheres and vermis. This phenotype of combined hydrocephaly, cerebellar malformations, and resulting death was 

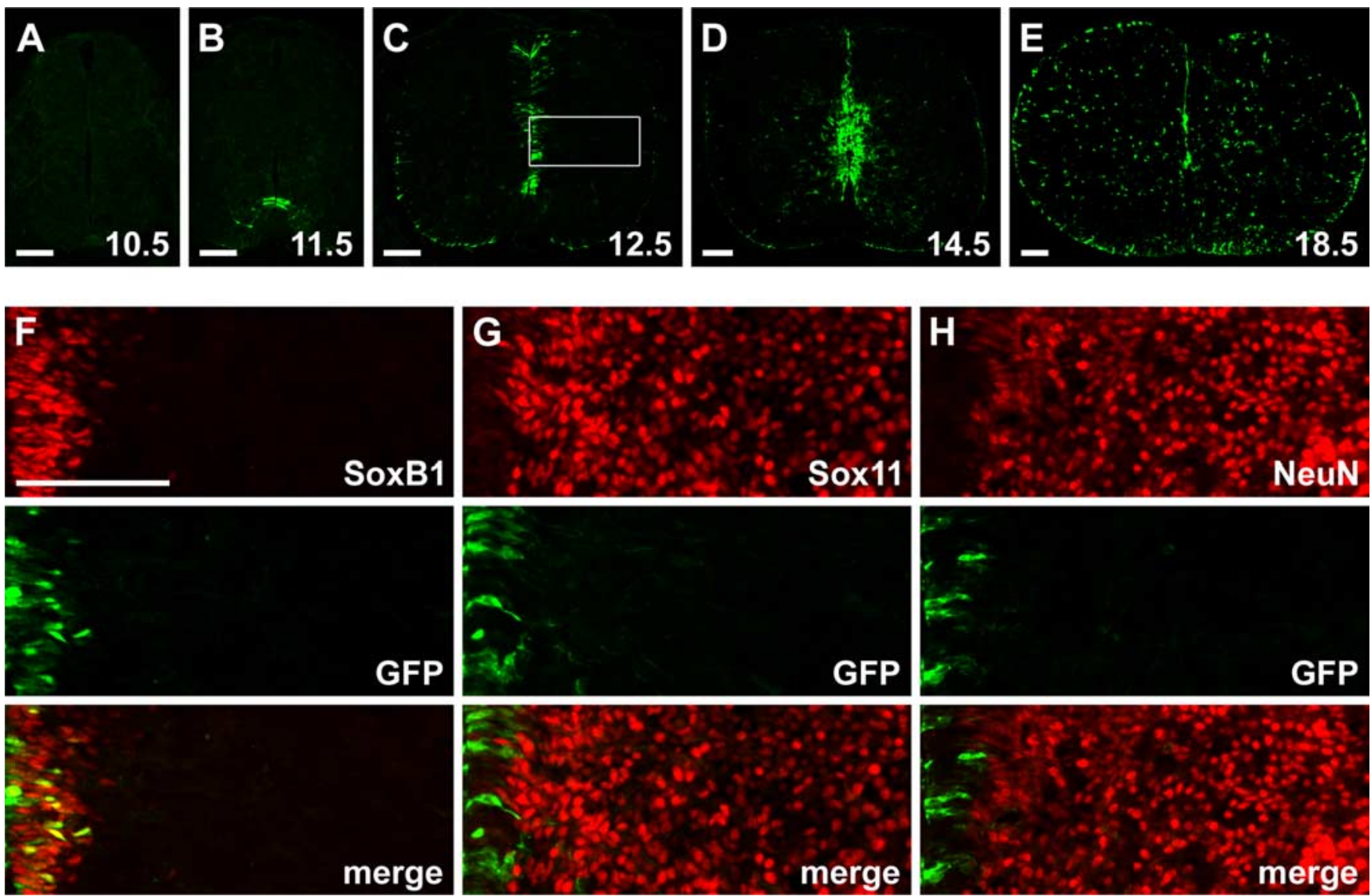

Figure 2. Embryonic expression pattern of the GFAP-Sox4 transgene. $\boldsymbol{A}-\boldsymbol{H}$, EGFP autofluorescence was used to determine transgene expression in the spinal cord of GFAP-Sox4 transgenic embryos at $10.5 \mathrm{dpc}(\boldsymbol{A}), 11.5 \mathrm{dpc}(\boldsymbol{B}), 12.5 \mathrm{dpc}(\boldsymbol{C}, \boldsymbol{F}, \boldsymbol{G}, \boldsymbol{H}), 14.5 \mathrm{dpc}(\boldsymbol{D})$, and $18.5 \mathrm{dpc}(\boldsymbol{E})$. The region boxed in $\boldsymbol{C}$ is magnified in $\boldsymbol{F}-\boldsymbol{H}$. $\boldsymbol{F}-\boldsymbol{H}$, Using immunohistochemistry with antibodies directed against SoxB1 (F), Sox 11 (G), and NeuN (H) (all in red), EGFP autofluorescence (in green) was detected in ventricular zone cells at 12.5 dpc but not in neuronal progenitors and neurons. Top, Staining for the stage-specific marker. Middle, Corresponding EGFP staining. Bottom, Merged pictures. Scale bars, $100 \mu \mathrm{m}$. The scale bar in $\boldsymbol{F}$ also applies to $\boldsymbol{G}$ and $\boldsymbol{H}$. The pattern is indicative of expression in radial glia and astrocytes.

fully penetrant. Therefore, we could not establish transgenic lines and had to perform all analyses on the direct offspring of the transgenic founders. Because of the limited number of transgenic animals available for the study, we focused on cerebellar development.

The Sox 4 transgene is expressed in radial glia and astrocytes of the developing cerebellum

As judged from EGFP autofluorescence, the transgene was not yet expressed in the cerebellar anlage at $12.5 \mathrm{dpc}$ (Fig. 3A) but was clearly detected $2 \mathrm{~d}$ later in cells throughout the ventricular zone of the cerebellum (Fig. 3B). By 18.5 dpc, EGFP-positive cells were predominantly found in deeper regions of the cerebellum in a dispersed pattern (Fig. 3C). Regions near the surface including the external granule cell layer contained few EGFP-positive cells, arguing that there is no significant transgene expression in most granule cell precursors.

To determine in closer detail the cell type in which transgene expression takes place, coimmunohistochemistry was performed with EGFP antibodies and markers for specific cell types in the developing cerebellum at P3, P9, and P15 (Fig. 3D-G and supplemental Fig. S1, available at www.jneurosci.org as supplemental material). EGFP expression was predominantly found in B-FABP-positive radial glia (Fig. $3 D$ and supplemental Fig. $\mathrm{S} 1 A, B$, available at www.jneurosci.org as supplemental mate- rial). In areas where GFAP-expressing cells were found, there also was a significant overlap between EGFP and GFAP, although coexpression was more difficult to visualize because of the different preferred subcellular localization of EGFP and GFAP (Fig. 3E and supplemental Fig. $\mathrm{S} 1 C, D$, available at www.jneurosci.org as supplemental material).

In contrast, very few Sox10-positive cells were labeled with EGFP at P3, and virtually none at P9 and P15 (Fig. 3F and supplemental Fig. $\mathrm{S} 1 E, F$, available at www.jneurosci.org as supplemental material). Because Sox10 is a marker for cells of the oligodendrocyte lineage, we conclude that residual EGFP might still be present in some oligodendrocyte precursors immediately after they have been generated. At later times, however, transgene expression is clearly restricted from oligodendrocytes. This is similarly true for granule cell precursors and differentiated neurons of the cerebellum, which at no time contained significant levels of EGFP (Fig. 3G, data not shown, and supplemental Fig. S1G, $H$, available at www.jneurosci.org as supplemental material).

Immunocytochemistry on primary cerebellar cultures confirmed that EGFP was exclusively expressed in B-FABP- and GFAP-positive cells (Fig. $3 H, I$ ) but not in Tuj1- or MAP2positive neurons (Fig. $3 J, K$ ). Taking into account that EGFP is confined to B-FABP- and GFAP-expressing cells and that expression of these markers is restricted to radial glia, including Bergmann glia, and astrocytes in the early postnatal cerebellum, we 

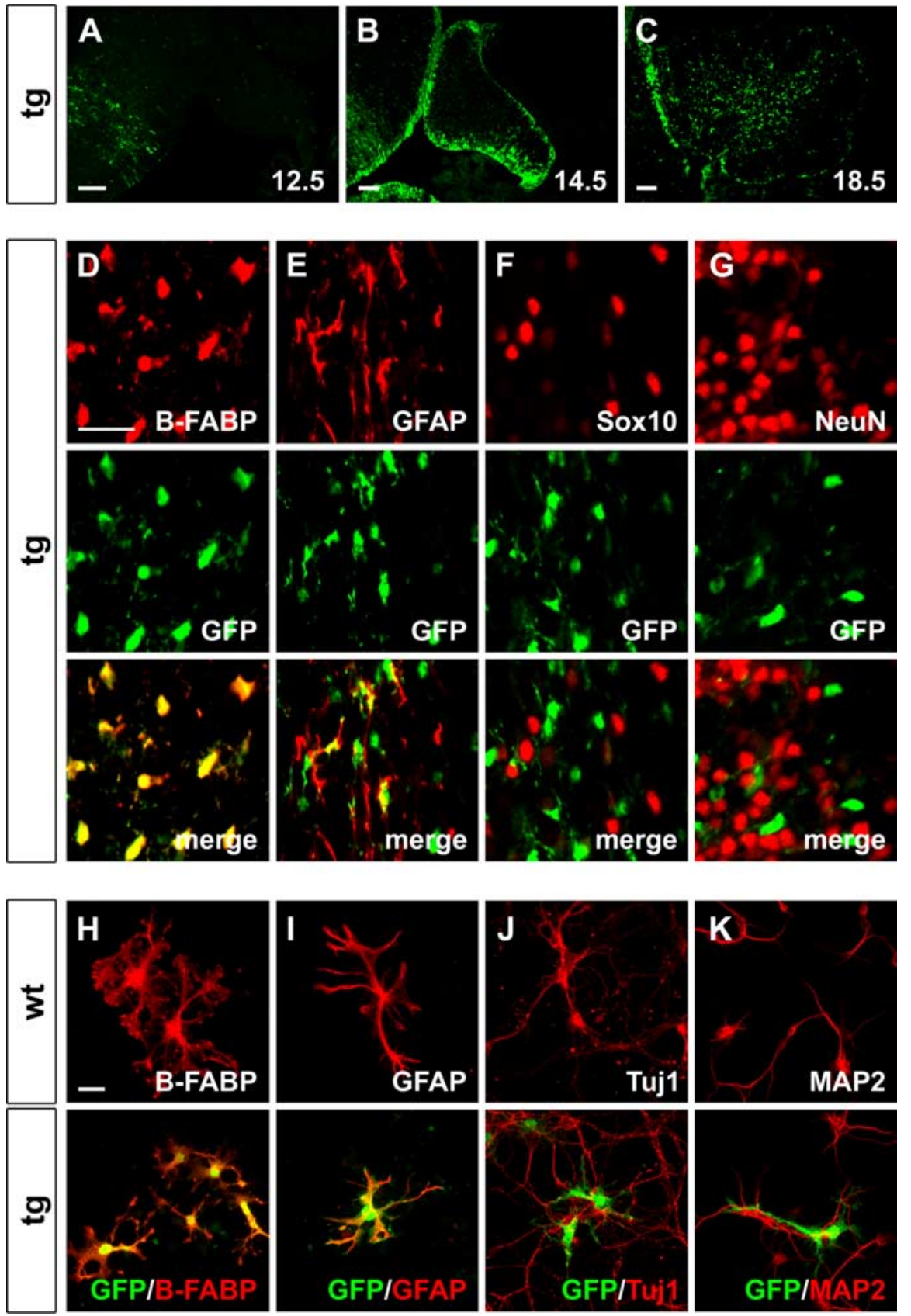

Figure 3. Expression of the GFAP-Sox4 transgene in the cerebellum and in cerebellar cultures. $A-C$, EGFP autofluorescence was used to determine transgene expression in the developing cerebellum of GFAP-Sox 4 transgenic embryos at $12.5 \mathrm{dpc}(\boldsymbol{A}), 14.5 \mathrm{dpc}$ $(\boldsymbol{B})$, and $18.5 \mathrm{dpc}(\boldsymbol{C})$ as indicated. $\boldsymbol{D}-\boldsymbol{G}$, Antibodies directed against B-FABP (D), GFAP $(\boldsymbol{E})$, Sox10 $(\boldsymbol{F})$, and NeuN $(\boldsymbol{G})$ as markers for specific cell types (all in red) were combined with antibodies directed against EGFP (in green) in coimmunohistochemistry on sections of transgenic cerebella at P9. Top, Staining for the cell-type specific marker. Middle, Corresponding EGFP staining. Bottom, Merged pictures. $\boldsymbol{H}-\boldsymbol{K}$, Antibodies directed against B-FABP $(\boldsymbol{H}), \operatorname{GFAP}(\boldsymbol{I})$, Tuj $1(\boldsymbol{J})$, and MAP2 $(\boldsymbol{K})$ as markers for specific cell types (all in red) were combined with antibodies directed against EGFP (in green) in coimmunocytochemistry on primary cell cultures prepared from wild-type (top) or GFAP-Sox4 transgenic (bottom) cerebella. Note that expression of the transgene overlaps both in vivo and in culture with B-FABP and GFAP staining, confirming expression in radial glia and astrocytes. Scale bars: $A-C, 100 \mu \mathrm{m}$; (in $\boldsymbol{D}) \boldsymbol{D}-\boldsymbol{G}, 25 \mu \mathrm{m}$; (in $\boldsymbol{H}) \boldsymbol{H}-\boldsymbol{K}, 25 \mu \mathrm{m}$. wt, Wild type; tg, transgenic. terparts from wild-type cultures. Additionally, they often lacked the endfeet-like structures at the end of the processes (Fig. $3 H, I)$. Despite these differences, they were still found in similarly close contact to cerebellar neurons as wild-type glia (Fig. 3J, K).

Transgenic cerebella exhibit an altered morphology

The overall impression of hypoplasia and reduced foliation in transgenic cerebella was confirmed in hematoxylin-eosinstained sections. At P3, size reductions were still minor. However, well defined lobules were only found in wild-type cerebella but were hardly recognizable in transgenic mice (Fig. $4 A, B$ ). The area below the surface was similarly enriched in nuclei in wild-type and transgenic mice, consistent with the presence of an external granule cell layer in both genotypes. The overall thickness of this external granule cell layer was unchanged in transgenic cerebella. Only areas that correspond to regions where fissures were already generated in the wild type exhibited a thickened external granule cell layer in transgenic cerebella. At P9, the difference in the fissurization of the cerebellar cortex was even more prominent (Fig. 4C,D). Fissures and lobules were still completely missing in transgenic mice at P15 (Fig. $4 E, F)$. With exception of the external granule cell layer, other layers remained absent in the cerebellar cortex of GFAPSox 4 transgenic mice.

Whereas proliferation rates were fairly normal in the external granule cell layer of GFAP-Sox4 transgenic cerebella at P3 (Fig. 5A,B), they were reduced in deeper regions of transgenic cerebella as indicated by a statistically significant $36 \%$ reduction in Ki67-positive cells outside the external granule cell layer (Fig. 5E). Alterations in proliferation thus likely contribute to the progressively increasing size difference between wild-type and transgenic cerebella during postnatal development. Rates of apoptosis that are high in the cerebellum during these early postnatal periods (Krueger et al., 1995) were additionally elevated in transgenic cerebella at P3 when analyzed by TUNEL staining, although the difference failed to reach statistical significance (Fig. 5C, D,F). conclude that the transgene predominantly occurs in radial glia and astrocytes.

Whereas neurons from GFAP-Sox4 transgenic cerebella were indistinguishable from those of wild-type cerebella (Fig. $3 J, K$ ), EGFP-expressing glia from GFAP-Sox 4 transgenic cerebella consistently exhibited shorter processes in culture than their coun-
Transgenic cerebella contain the major types of cerebellar neurons

Neuronal cell types of the cerebellum are identified by their location and a combination of immunohistochemical markers. External granule cells, for instance, are localized immediately below the pial surface and express Ki67 and Pax6 (Baader et al., 1999; 
Engelkamp et al., 1999). Ki67- and Pax6positive cells were not only present close to the pial surface in wild-type cerebella at P3 and $\mathrm{P9}$ but also in transgenic cerebella at all stages analyzed (Fig. 6A) (data not shown). Interestingly, Ki67-positive, proliferating granule cells were still present in transgenic cerebella at P15, when they are already absent in the wild type, arguing that their development may be slightly delayed or prolonged (Fig. $6 F$ ).

Only a minor fraction of cells in the external granule cell layer labeled weakly with NeuN (Fig. 6B, G), which marks the fraction of differentiating granule cells on their way from the external cell layer into deeper layers of the cerebellum (Weyer and Schilling, 2003). This was similarly observed in transgenic and wild-type cerebella. Differentiating and differentiated granule cells in deeper layers of wild-type cerebella express high levels of $\mathrm{NeuN}$ (Weyer and Schilling, 2003). NeuN immunoreactivity in deeper regions was also observed in transgenic cerebella, arguing that granule cells differentiate in this genotype despite the obvious absence of an orderly internal granule cell layer (Fig. $6 B, G)$.

Calbindin-positive neurons with large somata were also present in transgenic cerebella (Fig. 6C,H), indicating that Purkinje cells are specified and develop (Celio, 1990). These Purkinje cells exhibited dendritic arborizations and were also labeled with parvalbumin, demonstrating a proper maturation at the cellular level (Fig. 6C,H and data not shown). In contrast to the wild type, Purkinje cells in GFAP-Sox4 transgenic mice did not form a single cell layer but instead formed clusters deep in the cerebellar parenchyma where they intermingled with basket/stellate cells (Fig. 6, compare $C$, $H$ with $D, I$ ) (data not shown). These cerebellar interneurons are similarly positive for $\operatorname{ROR} \alpha$ and parvalbumin as Purkinje cells but can be differentiated from the latter by their smaller soma (Ino, 2004). Purkinje cell clusters, in contrast, only rarely contained NeuN-positive granule or Pax2positive Golgi cells (Weisheit et al., 2006) (Fig. 6, compare $C, H$ with $B, G$ and $E, J)$. In addition, Golgi cells intermingled with granule cells in GFAP-Sox 4 transgenic mice as they did in wildtype mice (Fig. 6, compare $E$, $J$ with $B, G$ ). Neurons either labeled by Pax 2 or parvalbumin were also present in deeper areas of transgenic cerebella (Fig. 6E,J) (data not shown). Pax2-positive neurons were mainly present within the white matter and correspond to precursor cells of GABAergic cerebellar interneurons, whereas parvalbumin-positive neurons of the cerebellar parenchyma represent cells of the deep cerebellar nuclei (Maricich and Herrup, 1999).

Despite the proper differentiation of major neuronal cell types within the cerebellar cortex and the appropriate sorting of cells, the layering was grossly disturbed. The orientation of Purkinje cell dendrites differed in transgenic cerebella from their regular orientation toward the pial surface, although they still showed a tendency for radial direction (data not shown). Compared with the wild type, the relative localization of internal granule cells and
Purkinje cells also appeared altered with more internal granule cells remaining between Purkinje cells and the cerebellar surface, as if they were stuck on their migratory route (Fig. 6B, G). We thus conclude that all major neuronal subtypes are present in transgenic cerebella. They differentiate but form clusters instead of organizing into the typical cerebellar layers.

\section{Bergmann glia fail to establish a radial glia phenotype in transgenic cerebella}

Because the Sox 4 transgene was not expressed in neuronal progenitors and neurons of the cerebellum and neuronal subtype specification and differentiation appeared fairly undisturbed, we looked into the development of glial cells. Cells expressing the transgene and marked by anti-EGFP antibodies were present in the cerebellum at all times of development analyzed (Fig. $7 A, D, G)$. Their distribution corresponded closely to the B-FABP staining pattern, arguing that most EGFP-expressing cells were radial glia (Fig. $7 B, E, H$ ). Staining for SoxB1 and Sox9 proteins as independent markers for radial glia (Pompolo and Harley, 2001; Sottile et al., 2006) confirmed this conclusion (supplemental Fig. $\mathrm{S} 2 A, B, D, E, G, H$, available at www.jneurosci.org as supplemental material). Cells expressing B-FABP, SoxB1 proteins, and Sox9 were found throughout transgenic cerebella from P3 to P15, whereas they become restricted to the Purkinje cell layer in wildtype cerebella (Fig. $7 B, E, H$ and supplemental Fig. $\mathrm{S} 2 A, B, D, E, G, H$, available at www.jneurosci.org as supplemental material).

Those B-FABP-labeled cells that were found in the Purkinje 


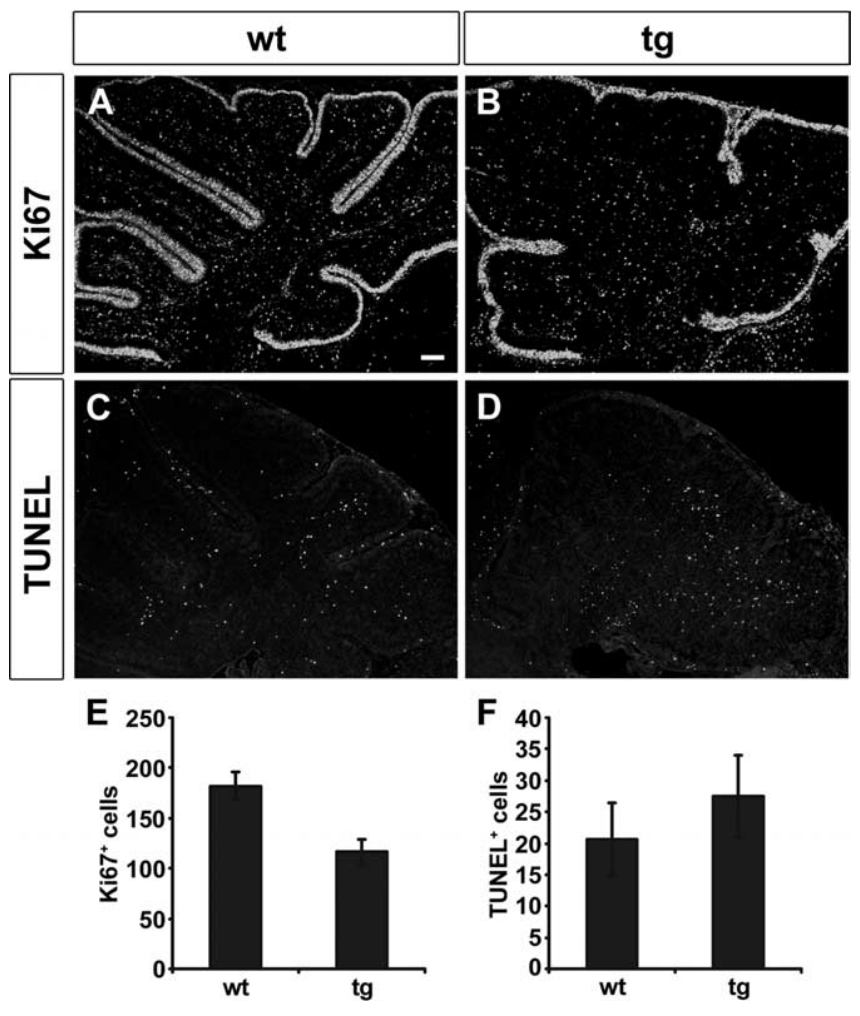

Figure 5. Apoptosis and proliferation in cerebella of GFAP-Sox 4 transgenic mice. $A, B, I m-$ munohistochemistry with antibodies specific for the proliferation marker Ki67 was performed on wild-type and transgenic cerebella at P3. C, D, Adjacent sections were used for TUNEL assays. $\boldsymbol{E}, \boldsymbol{F}$, Quantification of all Ki67-expressing cells outside the external granule cell layer $(\boldsymbol{E})$ and of TUNEL-positive cells $(\boldsymbol{F})$ in the cerebellum. At least 12 separate $10 \mu \mathrm{m}$ sections from two independent cerebella were counted for each genotype. Counted cells were normalized to cerebellar size and are presented per area unit as mean \pm SD. Differences to the wild type were statistically significant for proliferation rates in the mutant genotype ( $p \leq 0.001$ in $\boldsymbol{E}$ ) as determined by the Student's $t$ test. Scale bar: (in $A) A-D, 100 \mu \mathrm{m}$. wt, Wild type; $t$, transgenic

cell layer of wild-type cerebella extended long radially oriented fibers toward the pial surface, indicating their development to Bergmann glia (Fig. $7 B, E, H$ ). In contrast, B-FABP-labeled cells in transgenic cerebella failed to produce radial fibers (Fig. $7 B, E, H)$. GFAP, which labels both white-matter astrocytes in deeper regions of wild-type cerebella as well as Bergmann glia and their fibers in regions closer to the pial surface, was detected only in deeper regions of transgenic cerebella. This argues that whitematter astrocytes had formed but that the B-FABP-positive cells in superficial cerebellar regions had failed to mature into Bergmann glia in the presence of the Sox4 transgene (Fig. 7C, F,I). Results of RC2 staining also confirmed the absence of Bergmann glia and their radial fibers (data not shown). We thus conclude that the Sox4 transgene does not interfere per se with expression of glial markers but instead prevented radial glia from migrating to the characteristic position of Bergmann glia and from undergoing terminal differentiation and acquiring the fully differentiated Bergmann glia phenotype. Oligodendrocytes, in contrast, developed normally as evident from the rapid expansion of Sox10-positive cell numbers in deeper regions (supplemental Fig. S2C,F,I, available at www.jneurosci.org as supplemental material).

\footnotetext{
Alterations are also evident in the forebrain of GFAP-Sox 4 transgenic mice

Radial glia were also studied in the forebrain of GFAP-Sox4 transgenic animals. EGFP-positive radial glia were detected in
}

neonatal transgenic animals in numbers comparable to the wild type by antibody staining against B-FABP and SoxB1 (Fig. 8 A, $B$ and data not shown). At the day of birth, these forebrain radial glia possessed radial processes (Fig. $8 B$ ). Their orientation was, however, less regular in GFAP-Sox4 transgenic animals than in the wild type. Some radial processes in GFAP-Sox4 transgenic animals additionally failed to reach the pial surface (Fig. 8 B). At $\mathrm{P} 3$ and $\mathrm{P} 9$, radial fibers were no longer detectable in the cerebral cortex of GFAP-Sox4 transgenic mice using GFAP, B-FABP, or RC2 as markers, whereas they were still detectable in the wild type (Fig. $8 \mathrm{C}$ and data not shown). Starting at birth, forebrain radial glia thus also became progressively affected in GFAP-Sox 4 transgenic animals.

Resulting defects in neuronal layer formation were expected to be mild, because neuronal migration in the cerebral cortex is already well advanced at the day of birth (Bayer et al., 2004; Fukumitsu et al., 2006). Although minor aberrations and an overall thinning of the cerebral cortex were observed at $\mathrm{P} 9$, the principal layering was indeed present. This was evident from histological as well as immunohistochemical stainings for both calretininpositive nonpyramidal neurons in layers $1-3$ (Jacobowitz and Winsky, 1991) and Oct6-positive neurons in layers $2 / 3$ and 5 (Bermingham et al., 1996) (Fig. 8D-F). These results argue that the timing of the radial glia defect is critical for the severity of the resulting cytoarchitectural alterations.

At P15, the cerebral cortex had become even thinner, and the layering was now more difficult to discern (Fig. 8G,H). Neurons were densely clustered, their nuclear morphology had become very heterogeneous, and the number of apoptotic figures was increased (Fig. 8G). Calretinin-positive neurons showed unusually short and unbranched processes (Fig. $8 H$ ). However, these late changes in the cerebral cortex are likely degenerative and probably result from increasing hydrocephaly.

\section{Discussion}

Sox proteins of group C are abundantly expressed in the developing nervous system, and yet their function in nervous system development is just beginning to be understood (Wegner, 2005; Bergsland et al., 2006). Group C Sox proteins have proven especially difficult to study by loss-of-function studies in the mouse because of their significant overlap in expression and an at least partial functional redundancy (Kuhlbrodt et al., 1998; Cheung et al., 2000). As a result, severe nervous-system phenotypes were absent in Sox4-deficient as well as Sox11-deficient mice up until the time of their embryonic or perinatal death (Cheung et al., 2000; Sock et al., 2004).

Overexpression of a group C Sox gene is an alternative approach. In vivo, expression of group C Sox genes has been detected in neuronal precursors that were already specified but had not yet undergone terminal differentiation (Uwanogho et al., 1995). The same is true for glial cells (Kuhlbrodt et al., 1998). Because of this expression pattern, we chose the human GFAP promoter for overexpression of Sox4. This promoter has been shown to reliably drive transgene expression in radial glia as well as in the astrocyte lineage (Brenner et al., 1994; Nolte et al., 2001) and should allow us to analyze the consequences of transgene expression in an undifferentiated as well as in a differentiated cell type.

Phenotypic analysis of the resulting GFAP-Sox4 transgenic mice, first of all, proved that overexpression of Sox 4 interfered with normal CNS development, resulting in ataxia, hydrocephaly, and death at the end of the third postnatal week. The severe cerebellar ataxia was particularly intriguing. It was not attribut- 


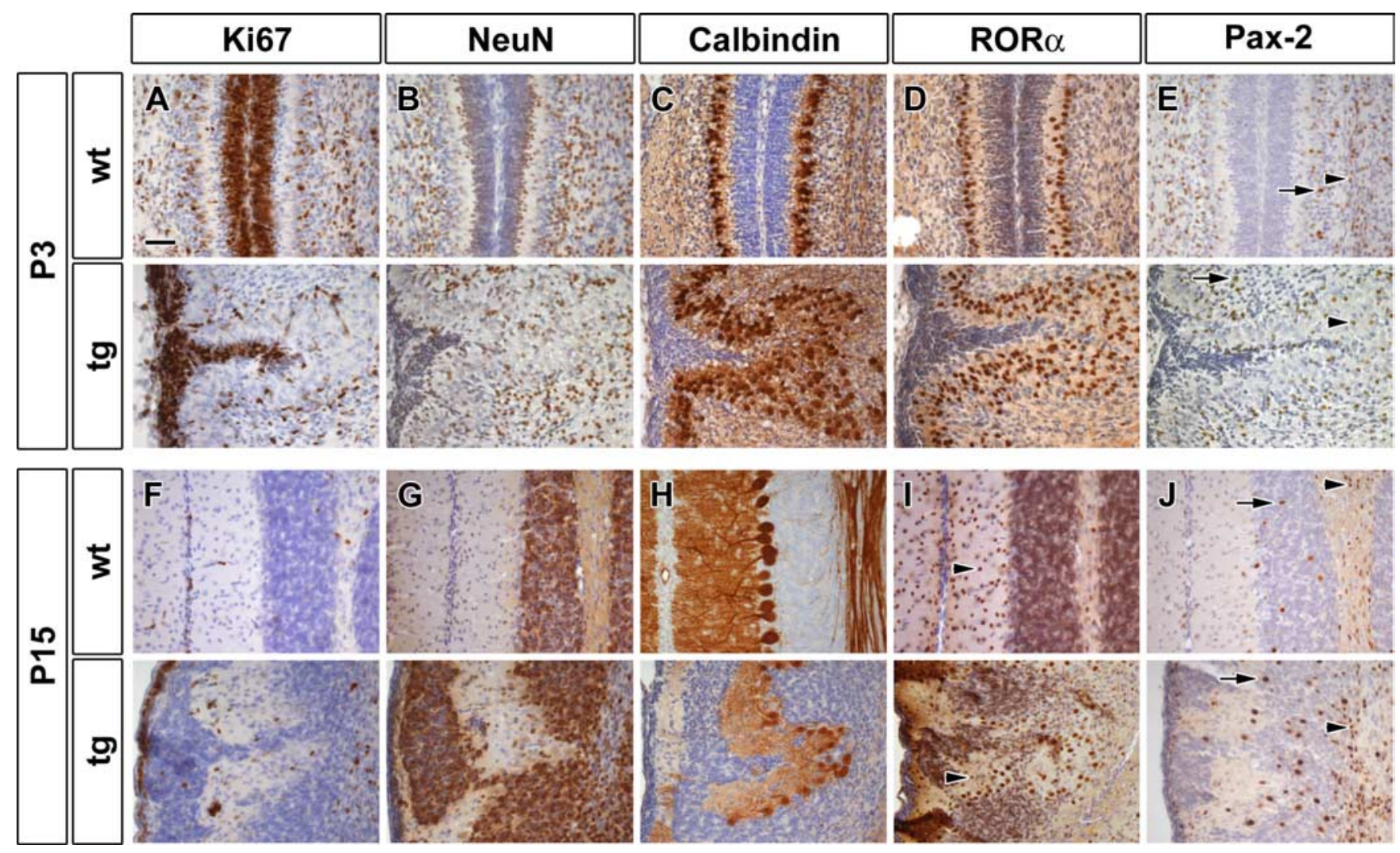

Figure 6. Analysis of neuronal subtypes in cerebella of GFAP-Sox4 transgenic mice. $\boldsymbol{A}-\boldsymbol{J}$, Immunohistochemistry was performed on paraffin sections of cerebella from wild-type (wt) and GFAP-Sox4 transgenic (tg) mice at P3 $(\boldsymbol{A}-\boldsymbol{E})$ and P15 (F-J) using antibodies directed against Ki67 $(\boldsymbol{A}, \boldsymbol{F})$, NeuN $(\boldsymbol{B}, \boldsymbol{G})$, calbindin D28K $(\boldsymbol{C}, \boldsymbol{H}), \operatorname{ROR} \alpha(\boldsymbol{D}, \boldsymbol{I})$, and Pax2 (E,J). All pictures depict areas around the central lobe. Scale bar, (in $A) 50 \mu \mathrm{m}$. Antibody staining is visible as a brown diaminobenzidine precipitate. Hematoxylin was used for counterstaining. Arrows point toward Golgi neurons. Arrowheads depict undifferentiated and differentiated basket/stellate cells within the white matter and molecular layer. All major neuronal subtypes are specified and mature in the transgenic cerebellum.

able to alterations in granule cell precursors, which represent a main site of Sox 4 expression in the postnatal cerebellum under wild-type conditions (Lee et al., 2002). They differentiate normally in our mouse model. Although the GFAP promoter is able to drive transgene expression in external granule cells under certain conditions (Marino et al., 2000), we did not obtain any evidence for significant expression of our GFAP-Sox4 transgene in external granule cells, in agreement with previous observations for a GFAP-HSV TK transgene (Delaney et al., 1996). Instead, the main sites of expression were ventricular zone cells with characteristics of radial glia and astrocytes. In neuronal progenitors, the GFAP-Sox4 transgene was efficiently turned off immediately on specification. Oligodendrocyte progenitors and mature oligodendrocytes likewise failed to express the GFAP-Sox4 transgene.

During embryonic development, radial glia did not appear to be severely affected, although the GFAP-Sox4 transgene was clearly and specifically expressed in these cells. What we failed to detect were cells that by localization and morphology correspond to Bergmann glia in the postnatal cerebellum. Unfortunately, there is no marker that exclusively labels mature Bergmann glia. All available markers, including B-FABP, SoxB1, Sox9, RC2, and GFAP, also mark immature radial glia and/or a fraction of astrocytes that are themselves highly heterogeneous (Mori et al., 2006). All of these markers continued to be expressed in transgenic cerebella. However, we were unable to detect cells in trans- genic cerebella that were labeled both by B-FABP and GFAP, a marker combination unique to Bergmann glia, thus confirming the absence of this cell type. We therefore conclude that the continuous expression of Sox 4 in radial glia is incompatible with the formation of the fully differentiated Bergmann glia phenotype. This influence of Sox4 expression on radial glia differentiation is also supported by the milder defect observed for radial glia in the postnatal cerebral cortex of transgenic animals.

Ablation of Bergmann glia or intrinsic Bergmann glia defects have previously been shown to affect the cerebellar architecture (Delaney et al., 1996; Kaartinen et al., 2001; Qu and Smith, 2005; Yue et al., 2005; Weller et al., 2006). Reported defects range from Bergmann glia loss and premature differentiation to relatively minor alterations in their localization or in the organization, length, and endfeet contacts of Bergmann glia processes. The severity of the Bergmann glia defect usually correlates with the degree to which the cerebellar architecture is disrupted, with granule cell migration affected in most cases and misplacement of other neuronal cell types only reported in the severer cases. Considering that Bergmann glia and their radial processes are absent in GFAP-Sox4 transgenic mice, cerebellar architecture should be severely disturbed in this mouse mutant. Indeed, the characteristic layering of the cerebellar cortex was not achieved in GFAPSox4 transgenic mice. Fissures and lobules did not form, although the major neuronal cell types were correctly specified and differentiated normally. Purkinje, basket, and stellate cells were 


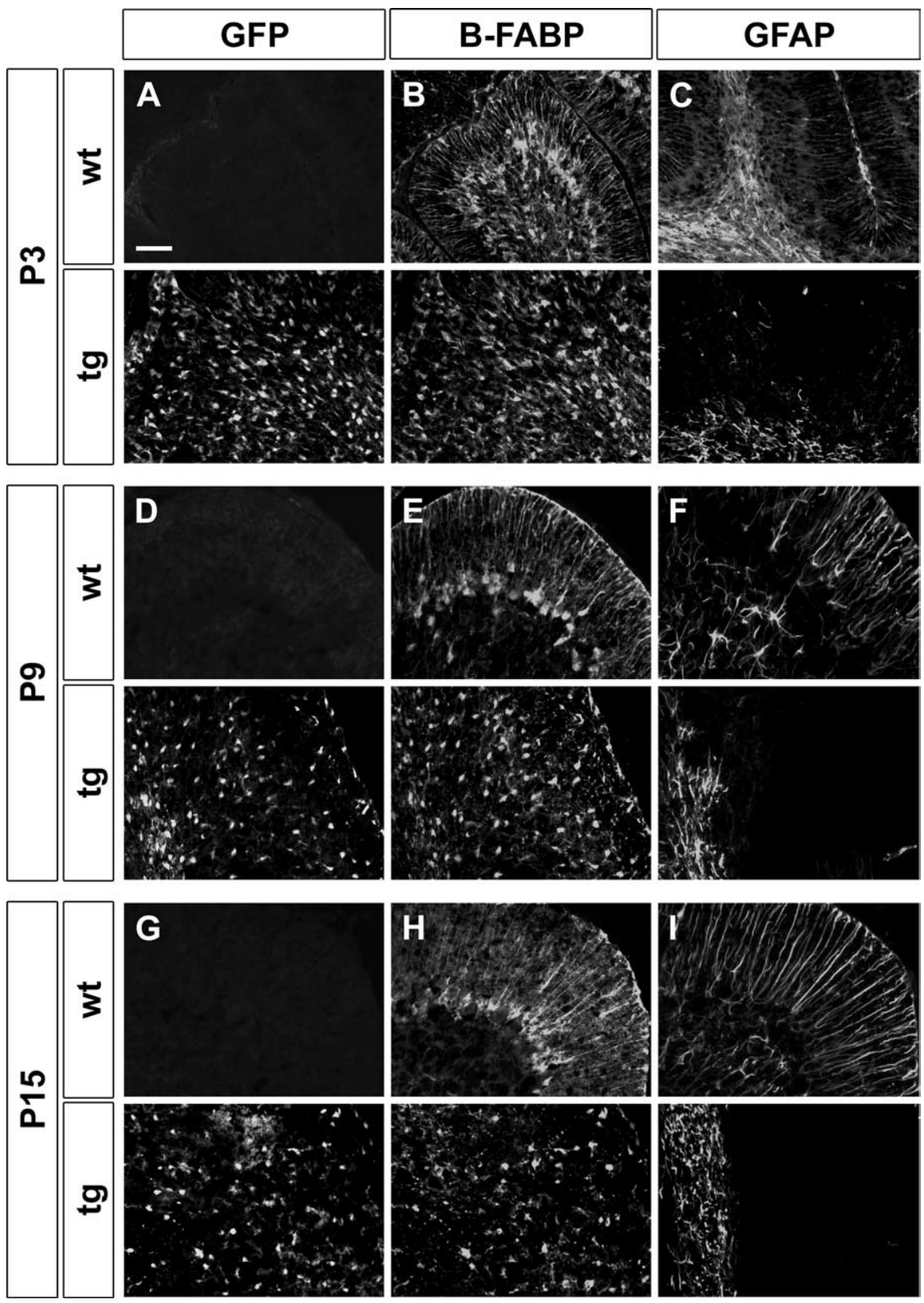

Figure 7. Analysis of glial cells in cerebella of GFAP-Sox4 transgenic mice. $\boldsymbol{A}-\boldsymbol{I}$, Immunohistochemistry was performed on sections of cerebella from wild-type (wt) and GFAP-Sox4 transgenic (tg) mice at P3 $(\boldsymbol{A}-\boldsymbol{C}), \mathrm{P9}(\boldsymbol{D}-\boldsymbol{F})$, and P15 (G-I) using antibodies directed against EGFP $(\boldsymbol{A}, \boldsymbol{D}, \boldsymbol{G})$, the radial and Bergmann glia marker B-FABP $(\boldsymbol{B}, \boldsymbol{E}, \boldsymbol{H})$, and the Bergmann glia and astrocyte marker GFAP $(\boldsymbol{C}, \boldsymbol{F}, \boldsymbol{I})$. Scale bar, (in $\boldsymbol{A}) 50 \mu \mathrm{m}$. Development of Bergmann glia was selectively disturbed.

not be ruled out. However, we consider this contribution to be minor because specification of GFAP-Sox4-expressing cells appeared normal and because GFAPSox4 expression was rapidly restricted from neuronal and oligodendrocytic progenitors after specification. The fact that neuronal and oligodendrocytic progenitors already contain substantial amounts of endogenous Sox4 and Sox11 (Uwanogho et al., 1995; Kuhlbrodt et al., 1998; Cheung et al., 2000) during the short initial phase where they may still contain residual amounts of Sox 4 expressed from the transgene furthermore argues against a strong influence of the GFAP-Sox4 transgene in neuronal or oligodendrocytic progenitors.

Interestingly, many granule cells moved from the external granule cell layer into deeper cerebellar tissues in the absence of radial fibers of Bergmann glia, which are believed to be essential for inward migration (Edmondson and Hatten, 1987; Zheng et al., 1996). Although we cannot rule out the transient existence of rudimentary radial fibers, our results seem to indicate that there is an alternative mechanism for granule cell migration in the absence of Bergmann glial fibers [e.g., binding to fibronectin (Hatten et al., 1982)]. This migratory path is, however, clearly less directional than in the wildtype situation.

On the basis of their expression pattern, SoxC proteins have been linked to neuronal as well as glial maturation (Hargrave et al., 1997; Kuhlbrodt et al., 1998). The current study suggests that the continuous presence of Sox 4 interferes with maturation of radial glia rather than promoting it. We thus like to propose a model in which the presence of SoxC proteins in glial precursors is normally needed to keep these precursors in an undifferentiated state and that SoxC gene expression needs to be shut off before full differentiation will occur. A similar suppressive function has been shown by overexpression studies for Engrailed-2 in Purkinje cells

found together, as were granule and Golgi cells, whereas intermingling between these groups was not observed, indicating that cell types are also appropriately sorted (Gliem et al., 2006). Nevertheless, neuronal subtypes failed to reach their proper destinations and instead aggregated in clusters. The absence of Bergmann glia is thus sufficient to explain the cerebellar phenotype of GFAP-Sox4 transgenic mice.

Intrinsic defects in cerebellar neurons or oligodendrocytes also lead to defects in cerebellar architecture (Goldowitz and Hamre, 1998; Mathis et al., 2003). Taking into account that neurons and oligodendrocytes can arise from cells that express the GFAP-Sox4 transgene, a neuronal or oligodendrocytic contribution to the cerebellar defect in GFAP-Sox4 transgenic mice can-
(Jankowski et al., 2004). This suggests that differentiation is the default pathway after final mitosis and that this process has to be blocked to keep a cell undifferentiated and migrating.

It is tempting to speculate that the hydrocephaly observed in GFAP-Sox 4 transgenic mice is also caused by a maturation defect of radial glia, because hydrocephaly is frequently observed in the absence or malfunction of ependymal cells that, similar to Bergmann glia, are derived from radial glia (Spassky et al., 2005). Although ependymal cells were present in transgenic mice and cilia were detected, the limited number of available animals prevented us from clarifying whether ependymal cells and their cilia are indeed fully functional. This needs to be addressed in future studies. 

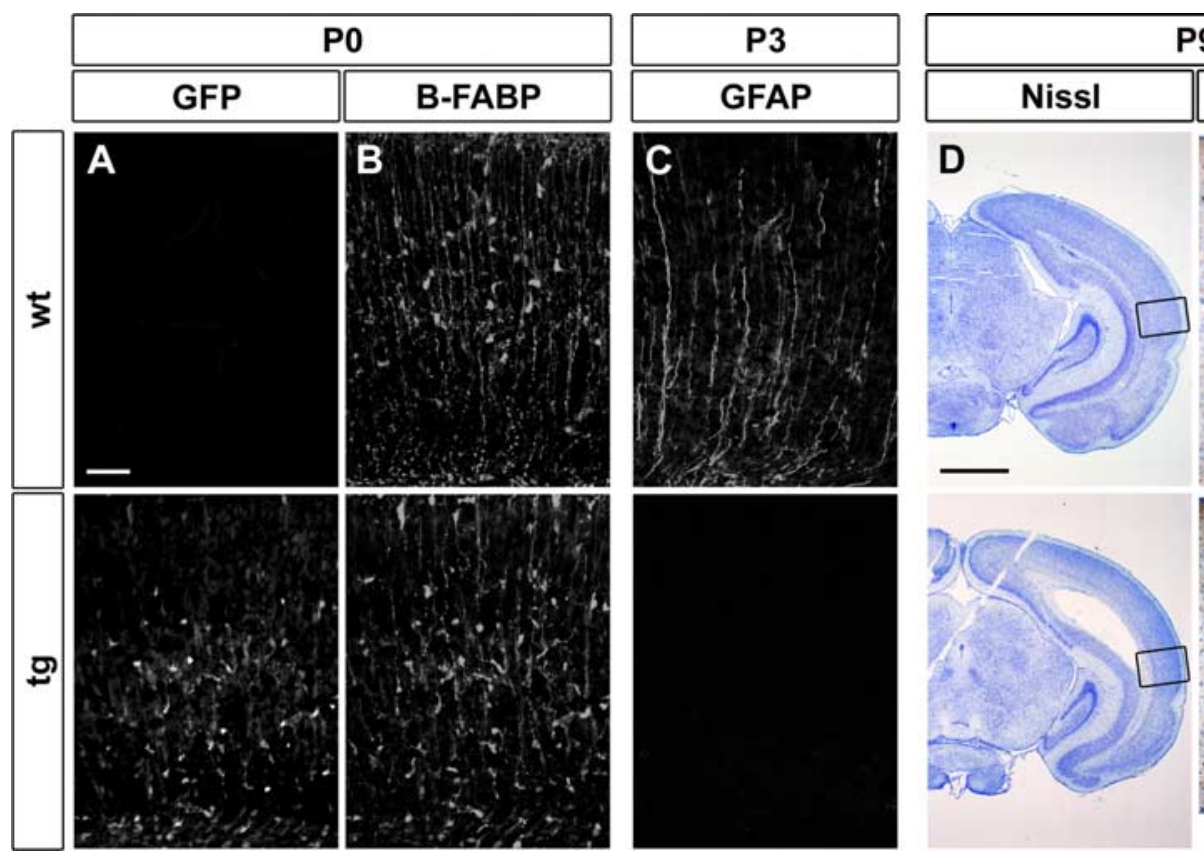
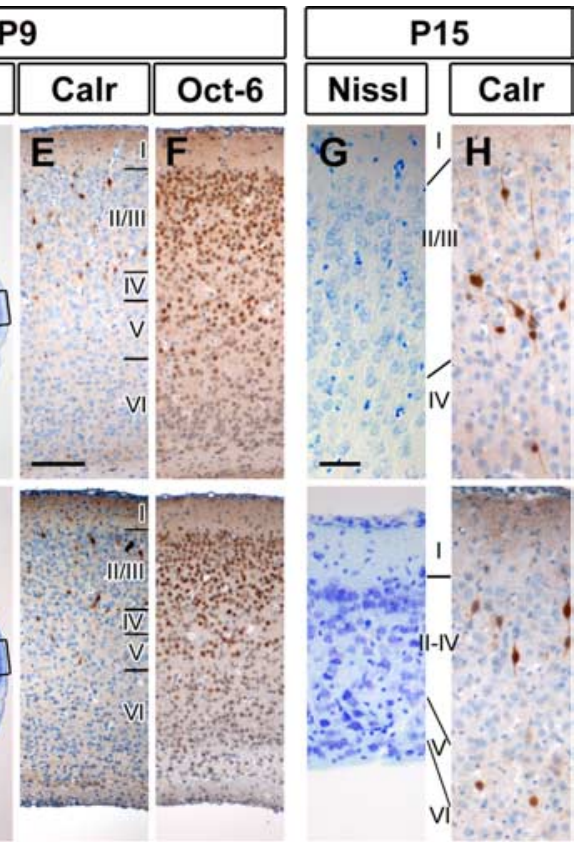

Figure 8. Analysis of the cortex of GFAP-Sox4 transgenic mice. $\boldsymbol{A}-\boldsymbol{H}$, Immunohistochemistry was performed on cortical sections (temporal lobe immediately dorsal to the prepiriform cortex) of wild-type (wt) and GFAP-Sox4 transgenic (tg) mice at the day of birth $(\boldsymbol{A}, \boldsymbol{B})$, at P3 $(\boldsymbol{C}), \mathrm{P9}(\boldsymbol{D}-\boldsymbol{F})$, and P15 $(\boldsymbol{G}, \boldsymbol{H})$ using antibodies directed against EGFP $(\boldsymbol{A}), \boldsymbol{B}-\mathrm{FABP}(\boldsymbol{B})$, GFAP $(\boldsymbol{C})$, calretinin $(\mathrm{Calr}$; $\boldsymbol{E}, \boldsymbol{H})$, and $0 \mathrm{ct}-6(\boldsymbol{F}) . \boldsymbol{D}, \boldsymbol{G}$, Nissl stainings at $\mathrm{Pg}(\boldsymbol{D})$ and $\mathrm{P} 15(\boldsymbol{G})$. The area in which higher magnifications were taken is boxed in $\boldsymbol{D}$. Scale bars: $\boldsymbol{A}-\boldsymbol{C}, 50 \mu \mathrm{m} ; \boldsymbol{D}, 1 \mathrm{~mm} ; \boldsymbol{E}, \boldsymbol{F}, 100 \mu \mathrm{m} ; \boldsymbol{G}, \boldsymbol{H}, 25 \mu \mathrm{m}$. Development of radial glia and layering in the forebrain were both disrupted with ongoing development.

\section{References}

Baader SL, Schilling K (1996) Glutamate receptors mediate dynamic regulation of nitric oxide synthase expression in cerebellar granule cells. J Neurosci 16:1440-1449.

Baader SL, Bergmann M, Mertz KD, Fox PA, Gerdes J, Oberdick J, Schilling K (1999) The differentiation of cerebellar interneurons is independent of their mitotic history. Neuroscience 90:1243-1254.

Bayer SA, Altman J, Chaper I (2004) Development in the rat nervous system. San Diego: Academic.

Bergsland M, Werme M, Malewicz M, Perlmann T, Muhr J (2006) The establishment of neuronal properties is controlled by Sox4 and Sox11. Genes Dev 20:3475-3486.

Bermingham JR, Scherer SS, O'Connell S, Arroyo E, Kalla KA, Powell FL, Rosenfeld MG (1996) Tst-1/Oct-6/SCIP regulates a unique step in peripheral myelination and is required for normal respiration. Genes Dev 10:1751-1762.

Bowles J, Schepers G, Koopman P (2000) Phylogeny of the SOX family of developmental transcription factors based on sequence and structural indicators. Dev Biol 227:239-255.

Brenner M, Kisseberth WC, Su Y, Besnard F, Messing A (1994) GFAP promoter directs astrocyte-specific expression in transgenic mice. J Neurosci 14:1030-1037.

Bylund M, Andersson E, Novitch BG, Muhr J (2003) Vertebrate neurogenesis is counteracted by Sox1-3 activity. Nat Neurosci 6:1162-1168.

Celio MR (1990) Calbindin D-28k and parvalbumin in the rat nervous system. Neuroscience 35:375-475.

Cheung M, Abu-Elmagd M, Clevers H, Scotting PJ (2000) Roles of Sox4 in central nervous system development. Mol Brain Res 79:180-191.

Delaney CL, Brenner M, Messing A (1996) Conditional ablation of cerebellar astrocytes in postnatal transgenic mice. J Neurosci 16:6908-6918.

Edmondson JC, Hatten ME (1987) Glial-guided granule neuron migration in vitro: a high-resolution time-lapse video microscopic study. J Neurosci 7:1928-1934.

Engelkamp D, Rashbass P, Seawright A, Van Heyningen V (1999) Role of Pax-6 in development of the cerebellar system. Development 126:3585-3596.

Friedrich R, Schlierf B, Tamm ER, Bösl MR, Wegner M (2005) The class III POU domain protein Brn-1 can fully replace the related Oct-6 during Schwann cell development and myelination. Mol Cell Biol 25:1821-1829.

Fukumitsu H, Ohtsuka M, Murai R, Nakamura H, Itoh K, Furukawa S
(2006) Brain-derived neurotrophic factor participates in determination of neuronal laminar fate in the developing mouse cerebral cortex. J Neurosci 26:13218-13230.

Gliem M, Weisheit G, Mertz KD, Endl E, Oberdick J, Schilling K (2006) Expression of classical cadherins in the cerebellar anlage: quantitative and functional aspects. Mol Cell Neurosci 33:447-458.

Goldowitz D, Hamre K (1998) The cells and molecules that make a cerebellum. Trends Neurosci 21:375-382.

Hargrave M, Wright E, Kun J, Emery J, Cooper L, Koopman P (1997) Expression of the Sox11 gene in mouse embryos suggests roles in neuronal maturation and epithelio-mesenchymal induction. Dev Dyn 210:79-86.

Hatten ME, Furie MB, Rifkin DB (1982) Binding of developing mouse cerebellar cells to fibronectin: a possible mechanism for the formation of the external granular layer. J Neurosci 2:1195-1206.

Ino H (2004) Immunohistochemical characterization of the orphan nuclear receptor ROR alpha in the mouse nervous system. J Histochem Cytochem $52: 311-323$

Jacobowitz DM, Winsky L (1991) Immunocytochemical localization of calretinin in the forebrain of the rat. J Comp Neurol 304:198-218.

Jankowski J, Holst MI, Liebig C, Oberdick J, Baader SL (2004) Engrailed-2 negatively regulates the onset of perinatal Purkinje cell differentiation. J Comp Neurol 472:87-99.

Kaartinen V, Gonzalez-Gomez I, Voncken JW, Haataja L, Faure E, Nagy A, Groffen J, Heisterkamp N (2001) Abnormal function of astroglia lacking Abr and Bcr RacGAPs. Development 128:4217-4227.

Krueger BK, Burne JF, Raff MC (1995) Evidence for large-scale astrocyte death in the developing cerebellum. J Neurosci 15:3366-3374.

Kuhlbrodt K, Herbarth B, Sock E, Enderich J, Hermans-Borgmeyer I, Wegner M (1998) Cooperative function of POU proteins and Sox proteins in glial cells. J Biol Chem 273:16050-16057.

Lee CJ, Appleby VJ, Orme AT, Chan WI, Scotting PJ (2002) Differential expression of SOX4 and SOX11 in medulloblastoma. J Neurooncol 57:201-214.

Maka M, Stolt CC, Wegner M (2005) Identification of Sox8 as a modifier gene in a mouse model of Hirschsprung disease reveals underlying molecular defect. Dev Biol 277:155-169.

Maricich SM, Herrup K (1999) Pax-2 expression defines a subset of GABAergic interneurons and their precursors in the developing murine cerebellum. J Neurobiol 41:281-294.

Marino S, Vooijs M, van Der Gulden H, Jonkers J, Berns A (2000) Induction 
of medulloblastomas in p53-null mutant mice by somatic inactivation of $\mathrm{Rb}$ in the external granular layer cells of the cerebellum. Genes Dev 15:994-1004.

Mathis C, Collin L, Borrelli E (2003) Oligodendrocyte ablation impairs cerebellum development. Development 130:4709-4718.

Mori T, Tanaka K, Buffo A, Wurst W, Kuhn R, Gotz M (2006) Inducible gene deletion in astroglia and radial glia-a valuable tool for functional and lineage analysis. Glia 54:21-34.

Nolte C, Matyash M, Pivneva T, Schipke CG, Ohlemeyer C, Hanisch UK, Kirchhoff F, Kettenmann H (2001) GFAP promoter-controlled EGFPexpressing transgenic mice: a tool to visualize astrocytes and astrogliosis in living brain tissue. Glia 33:72-86.

Pompolo S, Harley VR (2001) Localisation of the SRY-related HMG box protein, SOX9, in rodent brain. Brain Res 906:143-148.

Qu Q, Smith FI (2005) Neuronal migration defects in cerebellum of the Large (myd) mouse are associated with disruptions in Bergmann glia organization and delayed migration of granule neurons. Cerebellum 4:261-270.

Schilham MW, Oosterwegel MA, Moerer P, Ya J, Deboer PAJ, Vandewetering M, Verbeek S, Lamers WH, Kruisbeek AM, Cumano A, Clevers H (1996) Defects in cardiac outflow tract formation and pro-B-lymphocyte expansion in mice lacking Sox-4. Nature 380:711-714.

Sock E, Rettig SD, Enderich J, Bösl MR, Tamm ER, Wegner M (2004) Gene targeting reveals a widespread role for the high-mobility-group transcription factor Sox 11 in tissue remodeling. Mol Cell Biol 24:6635-6644.

Sottile V, Li M, Scotting PJ (2006) Stem cell marker expression in the Bergmann glia population of the adult mouse brain. Brain Res 1099:8-17.

Spassky N, Merkle FT, Flames N, Tramontin AD, Garcia-Verdugo JM, Alvarez-Buylla A (2005) Adult ependymal cells are postmitotic and are derived from radial glial cells during embryogenesis. J Neurosci 25:10-18.

Stolt CC, Lommes P, Sock E, Chaboissier M-C, Schedl A, Wegner M (2003) The Sox 9 transcription factor determines glial fate choice in the developing spinal cord. Genes Dev 17:1677-1689.
Tanaka S, Kamachi Y, Tanouchi A, Hamada H, Jing N, Kondoh H (2004) Interplay of SOX and POU factors in regulation of the nestin gene in neural primordial cells. Mol Cell Biol 24:8834-8846.

Uwanogho D, Rex M, Cartwright EJ, Pearl G, Healy C, Scotting PJ, Sharpe PT (1995) Embryonic expression of the chicken Sox2, Sox 3 and Sox11 genes suggests an interactive role in neuronal development. Mech Dev 49:23-36.

Wegner M (1999) From head to toes: the multiple facets of Sox proteins. Nucleic Acids Res 27:1409-1420.

Wegner M (2005) Secrets to a healthy Sox life: lessons for melanocytes. Pigment Cell Res 18:74-85.

Wegner M, Stolt CC (2005) From stem cells to neurons and glia: a soxist's view of neural development. Trends Neurosci 28:583-588.

Weisheit G, Gliem M, Endl E, Pfeffer PL, Busslinger M, Schilling K (2006) Postnatal development of the murine cerebellar cortex: formation and early dispersal of basket, stellate and Golgi neurons. Eur J Neurosci 24:329-343.

Weller M, Krautler N, Mantei N, Suter U, Taylor V (2006) Jagged 1 ablation results in cerebellar granule cell migration defects and depletion of Bergmann glia. Dev Neurosci 28:70-80.

Weyer A, Schilling K (2003) Developmental and cell type-specific expression of the neuronal marker NeuN in the murine cerebellum. J Neurosci Res 73:400-409.

Woods A, Sherwin T, Sasse R, MacRae TH, Baines AJ, Gull K (1989) Definition of individual components within the cytoskeleton of Trypanosoma brucei by a library of monoclonal antibodies. J Cell Sci 93:491-500.

Yue Q, Groszer M, Gil JS, Berk AJ, Messing A, Wu H, Liu X (2005) PTEN deletion in Bergmann glia leads to premature differentiation and affects laminar organization. Development 132:3281-3291.

Zheng C, Heintz N, Hatten ME (1996) CNS gene encoding astrotactin, which supports neuronal migration along glial fibers. Science 272:417419 . 